\section{rev Psi}

Revista de Psicología (UNLP)

https://revistas.unlp.edu.ar/revpsi

\title{
Interpretación y lazo social: introducción al dossier
}

Stella M. López ${ }^{1,2}$

Correspondencia

lopezstel@gmail.com

Filiaciones institucionales

${ }^{1}$ Facultad de Psicología, Universidad Nacional $\quad$ 2Escuela de Orientación Lacaniana (EOL, de La Plata (UNLP, Argentina)

\section{Resumen}

La Prof. Stella M. López, coordinadora del dossier "Interpretación y lazo social", presenta los contenidos del mismo.

\section{Palabras clave}

interpretación | lazo social | psicoanálisis | dossier

\section{Cómo citar}

López, S. M. (2021). Interpretación y lazo social: introducción al dossier. Revista de Psicología, 20(2), 139-143. HтTPs:// DX.DOI.ORG/10.24215/2422572XE136

\section{Proceso editorial}

Recibido

4 sep. 2021

Aceptado

4 sep. 2021
1 ra decisión

4 sep. 2021

Publicado

27 dic. 2021
ISSN

2422-572X

Licencia

Licencia de Cultura Libre CC-BY 4.0

(Compartir - Adaptar - Atribuir)

Entidad editora

RevPsi es una publicación de la

Facultad de Psicología (Universidad

Nacional de La Plata, Argentina) 


\section{Interpretação e o vínculo social: introdução ao dossiê}

\section{Resumo}

Prof. Stella M. López, coordenadora do dossiê "Interpretação e o vínculo social", apresenta seu conteúdo.

\section{Palavras-chave}

interpretação | vínculo social | psicanálise | dossiê

\section{Interpretation and the social bond: introduction to the dossier}

\section{Abstract}

Prof. Stella M. López, coordinator of the dossier "Interpretation and the social bond", presents its contents.

\section{Keywords}

interpretation | social bond | psychoanalysis | dossier 
El presente dossier surge como respuesta a la convocatoria "Interpretación y lazo social", mediante el cual se propuso un debate, inscrito en el psicoanálisis, de un tema actual. Tanto Freud como Lacan han logrado relacionar las nuevas formas del síntoma con el malestar en la cultura de su época, reflejando el valor subversivo del psicoanálisis respecto a los discursos imperantes.

El descubrimiento freudiano comprobó que, en transferencia, los síntomas no solo tienen un sentido, sino que también encierran una satisfacción, lo que signa los límites de la interpretación. Asimismo, Freud nos deja diversas indicaciones acerca del estatuto natural del síntoma como satisfactorio, al margen de la transferencia (Indart, 1998). Nos referimos a nociones que se despliegan con precisión a lo largo de la obra freudiana: la ventaja que el síntoma proporciona a nivel de los lazos sociales del sujeto, refugio en la enfermedad, y la ganancia primaria y secundaria de la misma. En Conferencias introductorias al psicoanálisis, Freud se refiere a esta última, enfrentándonos a su aspecto social, por ejemplo, dentro de los vínculos familiares y laborales, donde prima el costado de satisfacción en juego. Más claro aún, en su Conferencia XXIV, Freud agrega:
“(...) hay casos en que el propio médico tiene que admitir que el desenlace de un conflicto en la neurosis es la solución más inofensiva y la más llevadera desde el punto de vista social" (Freud, 2001, p. 348).

Esto, sin dejar de advertir que el médico sabe que en el mundo no hay una sola miseria neurótica, sino un penar real e incoercible, ya que el sacrificio de un hombre puede anudar una red social de satisfacciones consuelo, frente a lo real incoercible para muchos otros.

Para Freud, el inconsciente está, desde sus inicios, anudado a interpretación y transferencia. El dispositivo analítico devela la potencia de la palabra. De este modo, existe una homología entre la eficacia de la palabra en el síntoma y su uso en el dispositivo analítico, a la cual designamos: interpretación. "Hay palabras que alcanzan y otras no. Es lo que se llama la interpretación", dice Lacan, en Niza, en 1975. La interpretación es "un decir (que) pueda tener efectos", que va "más allá del charloteo al que, para decirlo, invitamos al sujeto que se confía a nuestros cuidados (...) llegan hasta a modificar" (Lacan, 1974, citado en Revista Lacaniana de Psicoanálisis, 2014, pp. 12 y13). Justamente, las psicosis confirman la eficacia del efecto de la palabra sobre el sujeto, cuestión ya señalada por la psiquiatría en el delirio interpretativo. A su vez, Miller plantea cómo la interpretación alcanza estructura de delirio, en tanto deduce que, en la neurosis, se trata de un desciframiento, que no de sentido (Miller, 1996).

Según Lacan, la importancia del aspecto social del psicoanálisis no pasa desapercibida, ni en sus aspectos clínicos, ni en los epistémicos o políticos. 
Tempranamente, en Función y campo de la palabra y del lenguaje del año 1953, Lacan expresa: "Mejor pues que renuncie quien no pueda unir a su horizonte la subjetividad de su época”. Y en su ultimísima enseñanza, en el Seminario XXIV, dice: "a pesar de todo hay que ser sensatos y darse cuenta de que la neurosis se sostiene en las relaciones sociales" (Lacan, 17 de mayo 1977).

En la experiencia analítica hay un real, el real propio del inconsciente del cual éste testimonia. Sin duda, el real lacaniano, que constituye nuestro rumbo, no es el de la ciencia. Tema no menor, que no solo interesa al psicoanálisis, sino también en su íntima vinculación con el malestar en la civilización. Cernir el papel que el psicoanálisis puede sustentar frente a los atolladeros de nuestra civilización resulta esencial, cuestión que Lacan plantea en el año 1967 cuando expresa que es a partir de los otros discursos "como lo real llega a flotar." (Lacan, 2012, p. 371)

El psicoanálisis, en tanto nuevo lazo social, es un campo donde se desarrolla una política de la cura, en la cual el analista no es libre. La clínica guiada por una política de la cura -su orientación a lo real- produce, llevada hasta el final, un psicoanalista. Así, en la Proposición del pase, de 1967, se introduce el procedimiento del pase para la nominación de los analistas. Lacan, siempre atento a los impasses de la civilización, señala la alianza entre el discurso científico y el discurso capitalista (Lacan, 1972), en el cual la relación a los objetos de goce es diferente a los del deseo. El discurso capitalista elude la castración, donde los objetos tecnos taponan la falta, creando la ilusión de la completud.

Dentro del presente dossier, dos artículos enfocan el malestar en el neoliberalismo. En el artículo de Ale, la interpretación analítica es situada como productora de una "verdadera mutación subjetiva", tanto en su acepción de sentido como de goce. A partir de la vertebración entre el malestar actual en la cultura y el lazo social, se interroga "¿sobre qué forma de lazo social intervenimos?" Ale destaca la diferencia con respecto a las acepciones clásicas en el campo de la sociología y la psicología, para circunscribir las que el sujeto mantiene con los discursos. Tras esto, se enfoca en el discurso capitalista -hoy neoliberal- en el cual la castración esta apartada, sosteniendo la promesa de felicidad y bienestar para todos.

En tanto, el artículo Neoliberalismo y subjetividad de Ibarra Ibáñez aborda las vicisitudes de las nuevas subjetividades producidas por el neoliberalismo. De este modo, el individualismo y la ruptura del lazo social en la subjetividad del neoliberalismo son situados como ejes de su desarrollo. Asimismo, desprende cómo el sujeto neoliberal está atrapado en una relación en el que el impulso hacia un exceso por fuera de sus límites no deja de suscitar stress, depresión, toxicomanía, suicidios, ataques de pánico, violencia.

Por su parte, el artículo de Ballesteros y González, a partir del Seminario Política lacaniana de J. A. Miller, lee la discontinuidad en la historia del psicoanálisis lacaniano con la excomunión de Lacan. Los autores privilegian como centro de la cuestión un real en juego en la formación de los analistas en el psicoanálisis, para lo cual, tras ubicar en el Acto de fundación de Lacan: "hay un agujero en el lugar del 
psicoanalista de la Escuela", revisan el texto de Bassols, La imposible identificación del analista, para interrogar en sus fundamentos la naturaleza del vínculo social. El artículo constituye un recorrido de lo que Lacan denomina el fin de análisis en sus dos versiones "atravesamiento del fantasma" e "identidad sinthomatica".

El trabajo titulado La interpretación no-toda y el lazo social, de Ramiro Tejo, alude a una presentación clínica en que la afectación del lazo social se encuentra en íntima vinculación con los efectos de un modo de funcionamiento de la interpretación. De tal modo, determinados sujetos se ven compelidos a un todo, lo cual significa que se convierte al sujeto en objeto del que escapa, confronta o se defiende, produciendo rupturas a nivel del lazo social. Precisa así cómo el discurso analítico ofrece al sujeto un partenaire inédito con quien afrontar las incidencias de lalengua, esta operación analítica puede establecer un límite a la vía delirante, en tanto el analista se incluya sosteniendo la lógica del no-todo.

Artaner, Verón y Jorge, en su artículo Un silencio hablante, sitúan el estatuto de la interpretación cuando lo que se pone en juego es el goce del síntoma. Resaltan la interpretación lacaniana que apunta a agotar el sentido y cercar el goce que lo habita, por lo que funciona al revés del inconsciente. Sus desarrollos sobre el lazo transferencial llevan a las autoras a enmarcar la interrogación sobre "la práctica virtual sin la presencia del cuerpo" en el lazo social inédito que implica la práctica analítica.

Para finalizar, antes de dejarlos con una lectura que, auguramos, será fructífera, se destaca que el presente dossier pretende ser otro aporte dentro de las articulaciones entre la interpretación y el lazo social, a los fines de promover la ampliación de saberes y la optimización del quehacer psicoanalítico.

\section{Referencias}

Freud, S. (2001). Obras completas, Tomo XVI. Amorrortu.

Indart, J. (1998). Los síntomas fuera de transferencia. En El síntoma charlatán (pp. 89-97). Paidós.

Lacan, J. (2014). El fenómeno lacaniano. Revista Lacaniana de Psicoanálisis, IX (16).

Lacan, J. (2012). Del psicoanálisis en sus relaciones con la realidad. En Otros escritos (pp. 371-380). Paidós.

Lacan, J. (2012). Proposición del 9 de octubre de 1967. Sobre el psicoanalista de la Escuela. En Otros escritos (pp. 261-277). Paidós.

Lacan, J. (2002). Función y campo de la palabra y del lenguaje en psicoanálisis. En Escritos 1 (pp. 227-310). Siglo XXI Editores.

Lacan, J. (1977). Clase del 17 de mayo de 1977. En Seminario 24 (pp. 9-20). Inédito.
Lacan, J. (12 de mayo de 1972). Del discurso psicoanalítico. Universidad de Milán. Inédito.

Miller, J. (1997-1998/2017). Política lacaniana. Colección Diva.

Miller, J. (1996). Entonces: “Sssh...”. Minilibros EOLIA.

Suarez, E. (2020-2021). Las violencias segregativas, efectos de la evaporación del padre. Tratamientos posibles. Proyecto I+D S071 (LIPPSI, Facultad de Psicología, UNLP).

Suarez, E. y Lopez, S. (2018-2019). La clínica en lo social: Inserción y desinserción en las adicciones a las drogas. Proyecto PPID/S021 2018-2019 (Facultad de Psicología UNLP). 